\title{
REVERSE DISCRIMINATION AND EFFICIENCY IN EDUCATION*
}

\author{
By GIANNI DE FRAJA ${ }^{1}$
}

University of Leicester and CEPR, U.K.

\begin{abstract}
This article shows that reverse discrimination policies can find a justification purely on efficiency grounds. We study the optimal provision of education when households belong to different groups, differing in the distribution of the potential to benefit from education among individuals, which is private information. The main result is that high-potential individuals from groups with relatively few high-potential individuals should receive more education than otherwise identical individuals from groups with a more favorable distribution of these benefits.
\end{abstract}

\section{INTRODUCTION}

In 1996, California approved Proposition 209, which forbids "discriminating against or giving preferential treatment to any individual or group in public employment, public education, or public contracting on the basis of race, sex, color, ethnicity, or national origin." The year before, the U.S. Supreme Court had ruled that the Banneker program at the University of Maryland was unconstitutional; this program provided financial assistance to blacks, and had lower ability thresholds for eligibility than the color-blind parallel program.

After the epochal changes brought about by the civil rights movement, sanctioned by the Supreme Court ruling that "race or ethnic background may be deemed a "plus' in a particular applicant's file,"2 the pendulum is therefore swinging back, and "reverse discrimination" legislation ${ }^{3}$ is now on the defensive, attacked both on equity and on efficiency grounds. Reverse discrimination policies, it is argued, are inequitable, as white individuals are discriminated against even

\footnotetext{
* Manuscript received March 2003; revised June 2004.

${ }^{1}$ I would like to thank Daniele Checchi, Ottorino Chillemi, David de Meza, Peter Dolton, Francesco Giovannoni, Clive Fraser, Daniel Seidmann, the editor, Antonio Merlo, and especially two anonymous referees of this Review, for many suggestions that have led to substantial improvement on previous drafts. Earlier versions of the article were presented to seminars in Leicester, York, Newcastle, Bristol, Southampton, Bologna, the Bank of Italy, Salerno, Granada, and Gerzensee, where I received helpful comments. Part of this research was carried out while I was visiting the University of Rome "Tor Vergata." Please address correspondence to: Gianni De Fraja, Department of Economics, University of Leicester, Leicester, LE1 7RH, United Kingdom. Phone: (+44) 0116252 3909. Fax: (+44) 0116252 2908. E-mail: defraja@le.ac.uk

${ }^{2}$ Regents of Univ. of California v. Bakke, 438 U.S. 265, 317.

${ }^{3}$ That is, according to the official definition used by the Clinton administration: "any effort taken to expand opportunity for women, and racial, ethnic and national origin minorities by using membership in those groups that have been subject to discrimination..." (Stephanopoulos and Edley, 1995, cited in Holzer and Neumark, 2000, p. 488). The three main areas where reverse discrimination has found application in the United States are university admissions in elite universities, favoritism in bidding for procurement, and hiring and promotion (Holzer and Neumark, 2000).
} 
though they bear no personal faults for the past suffering of individuals from other ethnic groups. They are also inefficient, because resources are not allocated to those with the highest willingness to pay or the highest potential to benefit.

This article identifies an efficiency rationale for an explicit policy of reverse discrimination in a utilitarian framework, where the decision maker's objective function is the maximization of total income, with no distributional considerations. We study the provision of education in the presence of individuals who differ both in their potential to benefit from education and according to some observable characteristic, such as race, sex, socioeconomic status, and so on.

The motivation of the article rests with our assumption, crucial but empirically plausible, that the distribution of the potential to benefit from education among individuals with a given set of observable characteristics is different from the distribution in the group of individuals with a different set of characteristics. Some groups are "disadvantaged": Individuals belonging to these groups are less likely to have high potential to benefit from education. These differences in the distribution of the potential to benefit from education, which we take as exogenous, may be due to a variety of causes: explicit or implicit discrimination, differences in social skills, and in the network of formal and informal contacts and connections that can be drawn upon to obtain favorable labor market outcomes, and even, though this is not necessary in our model, to differences in the distribution of cognitive ability in the different groups.

Our main result, in Section 3, is that the optimal education policy is such that individuals from disadvantaged groups pay a lower tuition fee for admission to a given education level (Proposition 3), and are enrolled to higher education levels than otherwise identical individuals from advantaged households (Proposition 2). This tallies, for example, with the practice of many U.S. universities to alter admission standards and financial assistance according to the ethnicity of the applicant (documented by Bowen and Bok, 1998), or with the U.K. government's current policy of expanding access to university by applicants from less advantaged backgrounds (DfES, 2003).

The result that the optimal policy is such that individuals in different groups are treated differently is a typical second-best result, being due to asymmetric information: If the government did not have an information disadvantage, identical individuals from different groups would, instead, be treated identically. It is also a qualitative distortion from the market outcome: In the absence of public intervention, all individuals with the same potential to benefit from education acquire the same education. What determines this result? To gain some intuition, begin by noting that individuals with high potential to benefit from education (in all groups) receive more education than they would acquire privately. This is due to the externality that justifies public intervention. To induce them to acquire these higher education levels, under asymmetric information, they must be offered a rent, in the form of a subsidy, financed by general taxation: They pay, in tuition fees, less than the monetary cost of their education. This subsidy has a social cost. Now note that, if there are relatively more high-potential individuals in a group than in another-which, given our definition, simply means that the first group is "advantaged"- then the aggregate cost of providing the high levels of education 
to individuals in that group is higher than for a group with fewer high-potential individuals. Therefore, to reduce the socially costly subsidy, high-potential individuals in advantaged groups are offered a lower subsidy and so choose to acquire less education than individuals with the same potential in "disadvantaged" groups. The article is devoted to making rigorous this loosely described intuition.

The literature analyzing reverse discrimination is scarce. The recent article by Wickelgren (2002) shows that a form of reverse discrimination may emerge in the absence of government intervention as part of the equilibrium behavior of profitmaximizing employers: Otherwise observationally identical individuals from disadvantaged groups are treated more favorably. This happens if ability is correlated across generations, and if parental income affects educational achievement: Because past discrimination lowers income, the expectation of an individual's ability, conditional on her educational achievement, is higher for individuals from disadvantaged groups, and, therefore, firms rationally expect them to perform better on the job, and pay them more.

Although reverse discrimination policies are controversial, those forbidding explicit discrimination against disadvantaged groups are less so: First, they are clearly equitable. Second, although some instances of inefficient discrimination, such as an employer's dislike for hiring members of racial minorities, are likely to be temporary, because discriminating employers lose out to profit-maximizing nondiscriminating instances (e.g., Becker, 1971; Lundberg and Starz, 1983), the theoretical literature has shown that inefficient discrimination may, in some situations, be part of the equilibrium behavior, and therefore is not eliminated without an explicit policy intervention. ${ }^{4}$

The article is organized as follows: Section 2 describes the model and Section 2.2 derives the behavior of households in the absence of any intervention. Results are discussed in Section 3. The problem faced by a welfare-maximizing government is set out in Section 3.1; the optimal education policy is derived formally in Section 3.2 and subsequently interpreted in Section 3.3. Section 3.4 discusses how this policy can be implemented using the natural instruments of tuition fees and financial assistance. Section 4 concludes.

\section{THE MODEL}

2.1. Household Characteristics. There is a continuum of households, with measure normalized to 1 . Each household comprises a parent and a child. The

\footnotetext{
${ }^{4}$ Typical is Coate and Loury's (1993) model of discrimination in the labor market. Individuals acquire human capital, and their productivity in employment depends on ability and human capital, which are both unobservable: Ability is the realization of a random variable (with the same distribution for all groups), and human capital is acquired. Employers only observe to which group an individual belongs, and use statistics about her group to infer her productivity. Coate and Loury show that there may be multiple equilibria. In one equilibrium all groups are treated equally. In another, employers believe that individuals belonging to a given group acquire less human capital and therefore pay them less, but, because of this, the rewards to, and therefore the incentives toward, human capital acquisition are weakened for individuals belonging to this group, and they will indeed acquire less human capital so that the employers' belief turns out to be correct. Other examples, in a similar spirit, are in Loury (2002, pp. 29-33). A different approach, leading to similar results, is Milgrom and Oster (1987).
} 
parent chooses the household's current consumption, the monetary transfer to the child (at the market interest rate, normalized to 0 ), and the investment in the child's education. The household utility function is given by

$$
u(b)+x, \quad u^{\prime}(b)>0, u^{\prime \prime}(b)<0, \text { there exists } b^{*} \text { such that } u^{\prime}\left(b^{*}\right)=1
$$

where $b>0$ is the household's current consumption and $x$ is the (possibly expected) amount of monetary resources enjoyed by the child, given by the sum of the monetary transfer from the parent and her labor market income, $y$. The latter is a function increasing in three arguments: her education, $e$, a parameter $\theta \in \mathbb{R}$, with positive support in $(\underline{\theta}, \bar{\theta})$, which measures a person's potential to benefit from education, and the general education level in the economy, $E: y=y(e, \theta, E){ }^{5}$ with $y_{\theta}(\cdot), y_{e}(\cdot)>0$ and $y_{E}(\cdot) \geqslant 0$. The variable $\theta$ captures the fact that some people are more capable of obtaining higher labor market income for a given education level: Ceteris paribus, an individual with high $\theta$ is one whose future income is higher. $y_{E}(\cdot) \geqslant 0$ implies that individuals are more productive if the general education level in the economy, $E$, is higher, ${ }^{6}$ and justifies public intervention in the provision of education. We assume $y(\cdot)$ also to satisfy $y_{e e}(\cdot)<0, \lim _{e \rightarrow \infty} y_{e}(\cdot)=0$, and $y_{e \theta}(\cdot)>0$. According to the latter, given two individuals with the same education, $e$, but different potential to benefit from education, $\theta$, the higher $\theta$ individual would benefit more from an increase in her investment in education. Although this is reasonable (and tallies, for example, with the practice followed by government bodies and charitable foundations to award scholarships according to ability), it is crucial for the qualitative nature of our results (a fuller discussion is in De Fraja, 2002). Finally, we make two technical assumptions on the third derivatives, $y_{e e \theta}(\cdot) \geqslant 0, y_{e \theta \theta}(\cdot) \leqslant 0$. These ensure that the appropriate incentive compatibility constraint is satisfied.

In addition to the potential to benefit from education, individuals also differ in race, sex, income, ethnic origin, nationality, immigrant status, religion, age, sexual orientation, socioeconomic status, and so on. Formally, we assume that each household belongs to one of $n$ groups, and that each group is characterized by a particular set of values for the child's observable characteristics. Groups are

\footnotetext{
${ }^{5}$ This function can be derived from primitives (De Fraja, 2002, pp. 440-41). An example, special but nevertheless capturing the essence of our idea, is that income is $z_{H}(e, E)$ with probability $\theta$, and $z_{L}(e, E)<z_{H}(e, E)$ with probability $(1-\theta)$.

${ }^{6}$ That is, $E$ bestows a positive externality. See Blaug (1965, especially pp. 234-41) or Cohn (1975, especially pp. 18-26, 127-29, 223-25), for comprehensive discussions of the potential sources of externality, West (1964), for the views of classical economists, or Lucas (1988) for a seminal formulation in the context of economic growth. An empirical estimate of the function $y(\cdot)$ can be found in the recent article by Moretti (2004). He calculates that a percentage point increase in the number of college graduates (corresponding here to an increase in $E$ ) "increases the wages of high school drop-outs and high school graduates by $1.9 \%$ and $1.6 \%$ respectively [and] of college graduates by $0.4 \%$ " (p. 175). These estimates indicate, plausibly, that $y_{e E}(\cdot)<0$, though this is not necessary to our results. More generally, the existence of a positive effect of $E$ on individual earnings is suggested by the productivity differences of low skilled workers across countries and by the "brain drain" of highly educated workers from less developed countries to countries with higher overall level of education. Hanushek (2002, pp. 2054-2055 and pp. 2064-2066) reports recent work on the topic.
} 
labeled by the subscript $i, i=1, \ldots, n$. The number of households in group $i$ is $h_{i}>0$, with $\sum_{i=1}^{n} h_{i}=1$.

Note that an individual's labor market income does not depend on her observable characteristics: Two equally educated individuals characterized by the same potential to benefit from education earn the same labor market income even when their skin color or sex is different.

Although individuals from different groups with the same $\theta$ are identical, groups do differ in a fundamental respect. We assume that the distribution of the capacity to benefit from education, $\theta$, is different in different groups: In group $i, \theta$ is distributed according to the function $\Phi_{i}(\theta)$ that has density $\phi_{i}(\theta)=\Phi_{i}^{\prime}(\theta)$ and monotonic hazard rate

$$
\frac{d}{d \theta}\left(\frac{1-\Phi_{i}(\theta)}{\phi_{i}(\theta)}\right) \leqslant 0, \quad \text { for every } \theta \in(\underline{\theta}, \bar{\theta}) \text { and for every } i=1, \ldots, n
$$

We capture the differences between these functions by the hazard rate, and, for the sake of simplicity, we assume that, given any two distributions $\Phi_{i}(\theta)$ and $\Phi_{j}(\theta)$, the difference between the hazard rates has a constant sign over the (common) support.

Assumption 1. Given $i, j \in\{1, \ldots, n\}$, either

$$
\frac{1-\Phi_{i}(\theta)}{\phi_{i}(\theta)} \leqslant \frac{1-\Phi_{j}(\theta)}{\phi_{j}(\theta)}, \quad \text { for every } \theta \in(\underline{\theta}, \bar{\theta})
$$

with strict inequality over a range, or

$$
\frac{1-\Phi_{i}(\theta)}{\phi_{i}(\theta)} \geqslant \frac{1-\Phi_{j}(\theta)}{\phi_{j}(\theta)}, \quad \text { for every } \theta \in(\underline{\theta}, \bar{\theta})
$$

with strict inequality over a range.

Relaxing this assumption would simply make our conclusions less clear-cut and more verbose in their description: We would need to burden our discussion with statement qualifiers such as "for individuals with $\theta$ up to...." Assumption 1 determines a natural ordering: Simply relabel the groups in such a way that Assumption 1 can be written, without further loss of generality, as follows.

Assumption 1 (a). For every $i \in\{2, \ldots, n\}$,

$$
\frac{1-\Phi_{i-1}(\theta)}{\phi_{i-1}(\theta)} \leqslant \frac{1-\Phi_{i}(\theta)}{\phi_{i}(\theta)}, \text { for every } \theta \in(\underline{\theta}, \bar{\theta})
$$

with strict inequality over a range. 
Lemma 1. Assumption 1(a) implies that $\Phi_{i}(\theta)$ first-order stochastically dominates $^{7} \Phi_{i-1}(\theta)$.

Proof.

$$
\frac{1-\Phi_{i-1}(\theta)}{\phi_{i-1}(\theta)} \leqslant \frac{1-\Phi_{i}(\theta)}{\phi_{i}(\theta)}, \quad \text { for every } \theta \in(\underline{\theta}, \bar{\theta})
$$

with strict inequality over a range implies

$$
\int_{-\infty}^{\theta} \frac{\phi_{i-1}(x)}{1-\Phi_{i-1}(x)} \mathrm{d} x \geqslant \int_{-\infty}^{\theta} \frac{\phi_{i}(x)}{1-\Phi_{i}(x)} \mathrm{d} x
$$

for every $\theta \in(\underline{\theta}, \bar{\theta})$, with strict inequality for $\theta$ above a certain value. Next, use the equality

$$
-\ln \left(1-\Phi_{i}(\theta)\right)=-\int_{-\infty}^{\theta} \frac{d \ln \left(1-\Phi_{i}(x)\right)}{d x} \mathrm{~d} x=\int_{-\infty}^{\theta} \frac{\phi_{i}(x)}{1-\Phi_{i}(x)} \mathrm{d} x
$$

to write (2) as $-\ln \left(1-\Phi_{i-1}(\theta)\right) \geqslant-\ln \left(1-\Phi_{i}(\theta)\right)$, implying $\Phi_{i-1}(\theta) \geq \Phi_{i}(\theta)$ with strict inequality over a range, and establishing the lemma.

That is, group 1 has the highest proportion of individuals with low potential to benefit from education, and group $n$ the lowest. It is therefore natural to label group 1 as the most "disadvantaged"; this term, though perhaps in general charged, describes accurately the specific setup of our model: The expected labor-market income-the expectation being taken over $\theta-$ of an individual with a given education in a group with a low index is lower than for an individual with the same education from groups with higher indices.

The interpretation of $\theta$, the measure of an individual's potential to benefit from education, is potentially controversial. In the present setup, it captures "everything that contributes to the child's income potential, is in the child at the time he takes his education decision, and cannot be purchased on the market" (Rubinstein and Tsiddon, 1998, p. 19). Instead of labeling $\theta$ as "ability" (Rubinstein and Tsiddon, 1998), or as "talent" (Bertola and Checchi, 2001), we prefer here the less concise "potential to benefit from education" in order to underline that the analysis of the article is not based on the view that the distribution of ability varies among racial and socioeconomic groups, as argued, for example, in the controversial book by Herrnstein and Murray (1994). A child's potential to benefit from education is affected both by her innate ability and by family, peer, and cultural pressures that hone skills and attitudes affecting employability and capacity to earn and which determine the network of connections and contacts that a person will be able to draw upon after entering the labor market: It matters who you know, as well

\footnotetext{
${ }^{7}$ Recall that, given two distribution functions $\Phi_{i}(\theta)$ and $\Phi_{j}(\theta)$ with common support, $\Phi_{i}(\theta)$ firstorder stochastically dominates $\Phi_{j}(\theta)$, if $\Phi_{i}(\theta) \leqslant \Phi_{j}(\theta)$ for every $\theta$ in the support, with strict inequality over a range.
} 
as who you are. Even though explicit discrimination is (increasingly) outlawed, ${ }^{8}$ catchphrases such as the "old boys network," "the glass ceiling," or "discrimination in contact" (Loury, 2002, pp. 95-6) do reflect the observation that certain groups in society enjoy a narrower range of opportunity than others, and will therefore have a less favorable distribution of $\theta$ than other groups, even though the distribution of innate ability may be the same (a formal analysis linking the potential to benefit from education to social background and innate ability is available on request or at www-users.york.ac.uk/ gd4/curres.htm\#aaee).

2.2. Decision in the Absence of Government Intervention. In the absence of public intervention, a household's budget constraint is given by $Y=k e+b+t$, where $Y$ is the household income, $t$ the intergenerational transfer, and $k>0$ the unit cost of privately provided education. A household's optimization problem is, therefore,

$$
\max _{e, t} u(Y-k e-t)+y(\theta, e, E)+t
$$

Let $e^{S}(\theta ; k)$ be the value of $e$ satisfying $k=y_{e}(\theta, e, E)$, and let $\underline{Y}$ be the lowest household income. Moreover, let $\bar{e}^{S}=e^{S}(\bar{\theta} ; k): \bar{e}^{S}$ be the amount of education that equates marginal cost and marginal benefit for the child with the highest $\theta$. We assume that

$$
\underline{Y} \geq b^{*}+k \bar{e}^{S}
$$

This is an important assumption: It states that even the poorest households (those with income $\underline{Y}$ ), where the child has the highest potential to benefit from education, $\bar{\theta}$, can finance the education level that equates marginal cost and marginal benefit, and still pay for consumption level $b^{*}$. In other words, no household is liquidity constrained..$^{9}$ An alternative assumption, which would not change our results, is that there are perfect capital markets. Clearly, neither assumption is realistic, but the point of the article is that reverse discrimination policies may be required by efficiency considerations even when other imperfections that affect different groups differently, such as capital market imperfections, have been eliminated by appropriate policy intervention. ${ }^{10}$

It is immediate to verify that in the absence of public provision, a household where the child has potential to benefit from education $\theta$ chooses an education level given by $e=e^{S}(\theta ; k)$, and intergenerational transfer given by $Y-b^{*}-$ $k e^{S}(\theta ; k)$ (note that, by (4), if the households that spend the most on education,

\footnotetext{
${ }^{8}$ See, however, Yinger (1998), Darity and Mason (1998), and Ladd (1998) for evidence of discrimination in consumer, labor, and credit markets.

${ }^{9}$ Note that $\bar{e}^{S}$ depends also on the overall level of education in the economy, $E$, and, therefore, whether (4) holds depends in general on the entire distribution of $\theta$ in all groups.

${ }^{10}$ The case where $t$ is constrained to be nonnegative and there are sufficiently poor households gives rise to situations where optimality requires differential treatment of individuals with different household incomes, and is analyzed in De Fraja (2002).
} 
those where the child has potential $\bar{\theta}$, can afford its cost, then so can all other households). The investment in education is carried out to the point where its marginal benefit, the increase in future income, equals its marginal cost, $k{ }^{11}$ The total household income is then distributed in such a way that the marginal benefit is 1 for both generations.

Note that household income has no effect on the amount invested in education, but simply affects intergenerational transfer. This is because a person's benefit from education does not depend on her parents' income. Income is, of course, one of the characteristics that distinguishes groups: Being born in a well-off household makes one more likely to have a high value of $\theta$ (see Solon, 1999, for a survey of the articles studying income correlation across generations). Household utility, denoted by $P(\theta, E)$, is given by

$$
P(\theta, E)=u\left(b^{*}\right)+y\left(\theta, e^{S}(\theta ; k), E\right)+Y-b^{*}-k e^{S}(\theta ; k)
$$

and is increasing in $\theta: P_{\theta}(\theta, E)=y_{\theta}\left(\theta, e^{S}(\theta ; k), E\right)>0$. That is, a household where the child has better labor market opportunity is better off.

\section{RESULTS}

3.1. The Problem of a Utilitarian Government. The government maximizes the utilitarian welfare function given by the unweighted sum of the utility of all households in the economy. The absence of any weighting of utility according to the position in the utility distribution rules out any possible redistributive preference in favor of some of the groups in the government objective function and therefore ensures that the optimality of reverse discrimination policies derived in Propositions 2 and 3 is due exclusively to efficiency considerations. Indeed, it is worth pointing out that here maximization of total utility is equivalent to the maximization of total income, because parents are interested in the maximization of their child's income and because all households consume the same amount, $b^{*}$, given in (1). Therefore, the policy we derive maximizes the monetary return of the investment in education.

To achieve its goal, the government selects the education-beyond a certain minimum, given by the compulsory level - to be received by each individual and the associated tuition fee. Both can be made conditional on the observable characteristics of the household, and on the child's potential to benefit from education, $\theta$, which however is not observable. Let, therefore, $e_{i}(\theta)$ denote the education level offered to a household belonging to group $i$ where the child has potential $\theta$, and $f_{i}(\theta)$ the tuition fee charged from this household. Different amounts may, of course, be charged from individuals in different groups for the same education,

\footnotetext{
${ }^{11}$ Given that, by construction, both the marginal benefits and the marginal costs are the same for all groups, so is the education level acquired by individuals of the same $\theta$. Individuals with higher $\theta$ acquire more education (this follows from $d e^{s}(\cdot) / d \theta=-y_{e \theta}(\cdot) / y_{e e}(\cdot)>0$ ). Therefore, on average, disadvantaged groups acquire less education: this is because, on average, they have fewer high $\theta$ individuals than more advantaged groups.
} 
but the government will need to respect a number of constraints, derived in what follows.

We begin by noticing that, given a policy $\left\{e_{i}(\theta), f_{i}(\theta)\right\}$, the household in group $i$ where the daughter has opportunity $\theta$ will, as before, choose a transfer $t$ to maximize $u\left(Y-f_{i}(\theta)-t\right)+y\left(\theta, e_{i}(\theta), E\right)+t$. This implies $u^{\prime}\left(Y-f_{i}(\theta)-t\right)=$ 1 , so that the optimal transfer $t^{*}$ is given by

$$
t^{*}=Y-f_{i}(\theta)-b^{*}
$$

Therefore, if $U_{i}(\theta)=u\left(Y-f_{i}(\theta)-t^{*}\right)+y\left(\theta, e_{i}(\theta), E\right)+t^{*}$ is the utility of a household in group $i$ where the daughter has opportunity $\theta$ who accepts the government offer, we can use (5) to write $U_{i}(\theta)$ as

$$
U_{i}(\theta)=u\left(b^{*}\right)+y\left(\theta, e_{i}(\theta), E\right)+Y-f_{i}(\theta)-b^{*}, \quad i=1, \ldots, n, \theta \in[\underline{\theta}, \bar{\theta}]
$$

Equation (6) holds provided that $f_{i}(\theta)-b^{*} \leqslant Y+y\left(\theta, e_{i}(\theta), E\right)$ : Households can afford to pay the tuition fee charged by the government without having to reduce their current consumption below $b^{*}$. We do not impose this as an explicit constraint, but verify that it holds at the solution. Next, note that the government cannot make a household accept a combination of education and tuition fee that makes the household worse off than it would be if it opted out of public provision by choosing private education. This is the first constraint

$$
U_{i}(\theta) \geq P(\theta, E), \quad i=1, \ldots, n, \quad \theta \in[\underline{\theta}, \bar{\theta}]
$$

A second constraint follows from the fact that households have an information advantage vis-à-vis the government: Unlike the household group, the child's potential to benefit from education is private information. This implies, in the standard fashion, that the government must ensure that the chosen policy satisfies the incentive compatibility constraint, which in this case implies ${ }^{12}$

$$
\frac{d U_{i}(\theta)}{d \theta}=y_{\theta}\left(\theta, e_{i}(\theta), E\right), \quad \frac{d e_{i}(\theta)}{d \theta} \geqslant 0, \quad i=1, \ldots, n, \quad \theta \in[\underline{\theta}, \bar{\theta}]
$$

${ }^{12}$ Equation (8) follows from a straightforward application of the revelation principle: The government must ensure that each household prefers "its" combination of education level and associated payment to all other combinations available to households in the same group. If a household where the child has potential $\theta$ chooses the combination designed for households of type $\hat{\theta}$, its utility would be given by

$$
\psi(\theta, \hat{\theta})=u\left(b^{*}\right)+y\left(\theta, e_{i}(\hat{\theta}), E\right)+Y-f_{i}(\hat{\theta})-b^{*}
$$

and so the first-order condition for choice of $\hat{\theta}$ is

$$
\frac{\partial \psi(\theta, \hat{\theta})}{\partial \hat{\theta}}=y_{e}\left(\theta, e_{i}(\hat{\theta}), E\right) \frac{d e_{i}(\hat{\theta})}{d \theta}-\frac{d f_{i}(\hat{\theta})}{d \theta}=0
$$

Truthful reporting implies that the first-order condition is satisfied at $\hat{\theta}=\theta$. From (6),

$$
\frac{d U(\theta)}{d \theta}=y_{\theta}\left(\theta, e_{i}(\theta), E\right)+y_{e}\left(\theta, e_{i}(\theta), E\right) \frac{d e_{i}(\theta)}{d \theta}-\frac{d f_{i}(\theta)}{d \theta}
$$

Substitute the above and $\hat{\theta}=\theta$ into $\left(^{*}\right)$ to obtain the first part of (8). The derivation of the second part of (8) is also standard, and can be found in De Fraja (2002, p. 460). 
The government must also, of course, satisfy a budget constraint. In view of the externality, we assume that the government subsidizes education by a fixed amount $T>0$. This, plus the tuition fees charged, must be sufficient to pay for the total education. $^{13}$

$$
T+\sum_{i=1}^{n} h_{i} \int_{\underline{\theta}}^{\bar{\theta}} f_{i}(\theta) \phi_{i}(\theta) \mathrm{d} \theta-\sum_{i=1}^{n} h_{i} \int_{\underline{\theta}}^{\bar{\theta}} k e_{i}(\theta) \phi_{i}(\theta) \mathrm{d} \theta \geqslant 0
$$

Deriving $f_{i}(\theta)$ from (6) and rearranging, the above becomes

(9) $u\left(b^{*}\right)+Y-b^{*}+T+\sum_{i=1}^{n} h_{i} \int_{\underline{\theta}}^{\bar{\theta}}\left[y\left(\theta, e_{i}(\theta), E\right)-U_{i}(\theta)-k e_{i}(\theta)\right] \phi_{i}(\theta) \mathrm{d} \theta \geqslant 0$

Finally, the overall level of education in the economy, denoted by $E$, is subject to a definitional constraint

$$
\sum_{i=1}^{n} h_{i} \int_{\underline{\theta}}^{\bar{\theta}} e_{i}(\theta) \phi_{i}(\theta) \mathrm{d} \theta=E
$$

We can now state formally the optimization problem faced by the government

$$
\max _{E,\left\{e_{i}(\theta), U_{i}(\theta)\right\}_{i=1}^{n}} \sum_{i=1}^{n} h_{i} \int_{\underline{\theta}}^{\bar{\theta}} U_{i}(\theta) \phi_{i}(\theta) \mathrm{d} \theta, \quad \text { subject to (7)-(10) }
$$

Toward solving (11), let $\beta$ and $\sigma$ be the Lagrange multipliers associated with constraints (9) and (10), respectively. That is, $\beta$ is the shadow cost of public funds, and $\sigma$ measures the marginal benefit of additional education in the economy. For given $k_{0}$, let $e_{i}^{G}\left(\theta ; \beta, k_{0}\right)$ be defined as the solution in $e$ of

$$
y_{e}(\theta, e, E)-k_{0}=\frac{\beta-1}{\beta} \frac{1-\Phi_{i}(\theta)}{\phi_{i}(\theta)} y_{e \theta}(\theta, e, E)
$$

and, for given $\beta>0, \sigma \geqslant 0$, and $k$, let

$$
k^{*}=k-\frac{\sigma}{\beta}
$$

Finally, let $\theta_{i}^{*} \beta, k_{0}$ be defined as the solution in $\theta$ of

$$
e^{S}(\theta ; k)=e_{i}^{G}\left(\theta ; \beta, k_{0}\right)
$$

${ }^{13}$ In De Fraja (2002), the subsidy $T$ and the associated taxes are derived as part of the government optimization problem. The qualitative features of the optimal education policy are the same as those derived here with the subsidy to the education sector exogenously set to $T>0$. An alternative approach leading to the same results is to assume an exogenously given value for the shadow cost of public funds, as in Laffont and Tirole (1993). 
if a solution exists, and by $\theta_{i}^{*}\left(\beta, k_{0}\right)=\underline{\theta}$ if $e^{S}(\underline{\theta} ; k)<e_{i}^{G}\left(\underline{\theta} ; \beta, k_{0}\right)$. Equation (12) is the standard optimality condition under asymmetric information when the cost of education is $k_{0}$ : The LHS is the difference between the marginal benefit and the marginal (social) cost for type $\theta$; the RHS is a positive correction factor, which is 0 for $\theta=\bar{\theta}$ (efficiency at the top), or when the shadow cost of public funds is 1 , and is positive otherwise (see Laffont and Tirole, 1993, p. 65).

3.2. The Optimal Education Policy. We can begin to determine the optimal policy for the government. The first proposition describes the provision of education for individuals with different potential to benefit from education within a given group.

Proposition 1. The education policy solving (11), $e_{i}^{*}(\theta)$, is given by

$$
e_{i}^{*}(\theta)=\left\{\begin{array}{ll}
e^{S}(\theta ; k) & \text { for } \theta<\theta_{i}^{*}\left(\beta, k^{*}\right) \\
e_{i}^{G}\left(\theta ; \beta, k^{*}\right) & \text { for } \theta \geqslant \theta_{i}^{*}\left(\beta, k^{*}\right)
\end{array} \quad i=1, \ldots, n\right.
$$

Moreover, the values of the multipliers in the solution are such that $\beta>1$ and $\sigma=\sum_{i=1}^{n} h_{i} \int_{\theta_{i}^{*}\left(\beta, k^{*}\right)}^{\bar{\theta}} y_{E}\left(\theta, e_{i}^{G}\left(\theta ; \beta, k^{*}\right), E\right) \phi_{i}(\theta) d \theta$.

Proof. (Sketch) The proof is a simplified version of the proof of Proposition 3 in De Fraja (2002). Here we report the main steps and devote an appendix (available on request from the author and at www-users.york.ac.uk/ gd4/ curres.htm\#aaee) to the technical details.

The proof begins by showing that the "participation constraint" (7) must be binding for some households: There must necessarily be someone who is indifferent between state and private provision.

Lemma A1. For every $i=1, \ldots, n$, it cannot be that $U_{i}(\theta)>P(\theta, E)$ for every $\theta \in[\underline{\theta}, \bar{\theta}]$.

In the second step, it is shown that if there are households whose utility is strictly above their reservation level, then all households with higher $\theta$ in the same group also enjoy utility strictly above their reservation level.

Lemma A2. For every $i=1, \ldots, n$, let there exist $\hat{\theta}_{i} \in[\underline{\theta}, \bar{\theta})$ and $\delta>0$ with $U_{i}(\theta)>P(\theta, E)$ for $\theta \in\left(\hat{\theta}_{i}, \hat{\theta}_{i}+\delta\right)$. Then $U_{i}(\theta)>P(\theta, E)$ for (almost) every $\theta \in\left(\hat{\theta}_{i}, \bar{\theta}\right]$.

That is, by Lemma A2, in each group there is a cutoff level of $\theta, \hat{\theta}_{i} \in[\underline{\theta}, \bar{\theta}]$ such that households with $\theta$ below this cutoff only receive their reservation utility, and households with higher $\theta$ receive strictly more. The next lemma is the core of the proof: It draws the implication of Lemma A2 for the education received by the daughters in these two groups of households.

LemMA A3. $e_{i}^{*}(\theta)=e^{S}(\theta ; k)$ for $\theta<\hat{\theta}_{i}, e_{i}^{*}(\theta)=e_{i}^{G}\left(\theta ; \beta, k^{*}\right)$ for $\theta \geqslant \hat{\theta}_{i}$. 
In other words, this establishes that individuals below the cutoff point derived in Lemma A2 receive the same education that they would acquire privately, whereas individuals with $\theta$ above this cutoff receive more education: They receive the second-best education level when the cost is $k^{*}$.

We now show that for (at least) some groups, there is a positive measure of households who are in the group above the cutoff $\theta$ obtained in Lemma 2, that is, who receive strictly more utility that they obtain from private provision.

Lemma A4. There exists $i \in\{1, \ldots, n\}$ such that $\hat{\theta}_{i}<\bar{\theta}$.

This is a consequence of the positive transfer to the education sector, $T>0$.

Next, $e_{i}^{*}(\theta)$ is continuous, and therefore that $\theta_{i}^{*}$ is in fact equal to $\hat{\theta}_{i}$ and given by the condition $e^{S}\left(\theta_{i}^{*} ; k\right)=e_{i}^{G}\left(\theta_{i}^{*} ; \beta, k^{*}\right)$.

Lemma A5. For every $i=1, \ldots, n, e_{i}^{*}(\theta)$ is continuous.

The next lemma shows that there are individuals above the cutoff point.

Lemma A6. For every $i=1, \ldots, n$, there exists $a>0$ such that $e_{i}^{*}(\theta)=e_{i}^{G}(\theta ; \beta$, $k^{*}$ ) for (almost) every $\theta \in[\bar{\theta}-a, \bar{\theta}]$.

To summarize these lemmata, they show that households are divided into two subsets, those that receive the same education they would acquire privately and those that receive more (Lemma A3), and that the latter set has positive measure (Lemma A6). For individuals in the latter subset Lemma A3 determines $e_{i}^{*}(\theta)$.

This therefore establishes the main body of the proposition. There are a few "loose ends" to tidy up. Begin with the value of $\sigma$ : This follows immediately, using (7.120) in Leonard and van Long (1992, p. 255), and differentiating the Lagrangean of problem (11) with respect to $E$. We also need to show that $e_{i}^{*}(\theta)$ is increasing in $\theta$. Clearly, $e^{S}\left(\theta_{i}^{*} ; k\right)$ is increasing in $\theta$. When $\theta \geqslant \theta_{i}^{*}$, totally differentiate (12) and rearrange

$$
\frac{d e_{i}^{G}\left(\theta ; \beta, k^{*}\right)}{d \theta}=\frac{\frac{1-\Phi_{i}(\theta)}{\phi_{i}(\theta)} y_{e \theta \theta}(\cdot)+\left(\frac{d}{d \theta}\left(\frac{1-\Phi_{i}(\theta)}{\phi_{i}(\theta)}\right)-\frac{\beta}{\beta-1}\right) y_{e \theta}(\cdot)}{\frac{\beta}{\beta-1} y_{e e}(\cdot)-\frac{1-\Phi_{i}(\theta)}{\phi_{i}(\theta)} y_{e e \theta}(\cdot)}
$$

In view of the technical assumptions on the third derivative, the above is positive, establishing that $e_{i}^{*}(\theta)$ is increasing.

The proof is based on the assumption that $\beta>1$. We now show that this must hold. By contrast, if $\beta=1$, then all households receive the same education given by

$$
y_{e}\left(\theta, e^{S}(\theta, k-\sigma), E\right)=k-\sigma \quad i=1, \ldots, n \quad \theta \in[\underline{\theta}, \bar{\theta}]
$$

Notice that an increase in $e$ increases $E$, which in turn increases $e$; since $\lim _{e \rightarrow \infty} y_{e}(\cdot)=0$, the benefit of education eventually falls below its cost and society cannot finance a large-enough education level with a fixed budget. 
The final thing to establish is that $f_{i}(\theta)$ is set at a level that allows everybody the optimal rate of consumption $b^{*}$. Clearly, this is the case for the households that receive the same education as they would purchase privately, but just as clearly, for the other households, which have more utility than they would receive privately: If it were not the case, it would be possible to increase the value of the objective function by reducing the education provided to these households, and increasing their current consumption.

To interpret Proposition 1, begin by noting that $k^{*}$ is the social cost of education. This is given by the monetary cost, $k$, reduced by the social benefit, $\sigma$, in turn reduced to take the shadow cost of public funds, $\beta$, into account. If $y_{E}(\cdot)=0$, then $\sigma=0$ and $e_{i}^{*}(\theta)=e^{S}(\theta ; k)$, for every $i=1, \ldots, n$, for every $\theta \in[\underline{\theta}, \bar{\theta}]$, and $T$ is transferred in cash to the household sector. In other words, the optimal policy is "do nothing," let the market operate undisturbed. This is natural: With no external effects of education, and no capital market imperfections, private provision is efficient, and the government simply duplicates it. If, instead, $y_{E}(\cdot)>0$ for at least some $e>e^{S}(\underline{\theta}, k)$, then $\sigma>0$, and therefore $k^{*}<k$. This implies that the individuals with the highest opportunity (those for whom $\theta=\bar{\theta}$ ) receive strictly more education under public provision than they would purchase privately: See (12) when $\theta=\bar{\theta}$. Since $e_{i}^{*}(\theta)$ is continuous, this is also true for individuals whose $\theta$ is "close" to $\bar{\theta}$. On the other hand, individuals for whom $\theta$ is sufficiently low receive the same education they would receive if they acquired education privately.

The intuition for the particular shape of the relationship between opportunity and education for individuals in a given group is standard. Optimality requires that the education level decrease sharply as $\theta$ decreases. This is to provide a sufficient disincentive for those who have high potential to benefit from education to mimic the behavior of those with low potential: Since the former benefit more from education than the latter (as $y_{e \theta}(\cdot)>0$ ), it is more expensive for high $\theta$ individuals to give up education for a given reduction in the tuition fee. This, however, cannot be pushed too far: For individuals with very low $\theta$, the education level $e_{i}^{G}\left(\theta ; \beta, k^{*}\right)$ becomes too low, and they would opt out of public provision (De Fraja, 2002, p. 452).

The next proposition is the main result of this article. It states that the optimal education policy is such that individuals from disadvantaged groups receive more education than individuals with the same potential to benefit from education in more advantaged groups.

Proposition 2. Let Assumption 1(a) hold; then $e_{i-1}^{*}(\theta)>e_{i}^{*}(\theta)$, for every $i=2, \ldots, n$, for every $\theta \in\left(\theta_{i-1}^{*}\left(\beta, k^{*}\right), \bar{\theta}\right)$.

This is a striking result. It provides a rationale for reverse discrimination purely on efficiency grounds, with no appeal to equity or redistributive reasons whatsoever. Individuals from a disadvantaged group are treated, other things equal, more favorably precisely because of their appurtenance to the group.

Figure 1 illustrates Proposition 2; it depicts, for two groups, the education received as a function of an individual's potential to benefit from education. The 


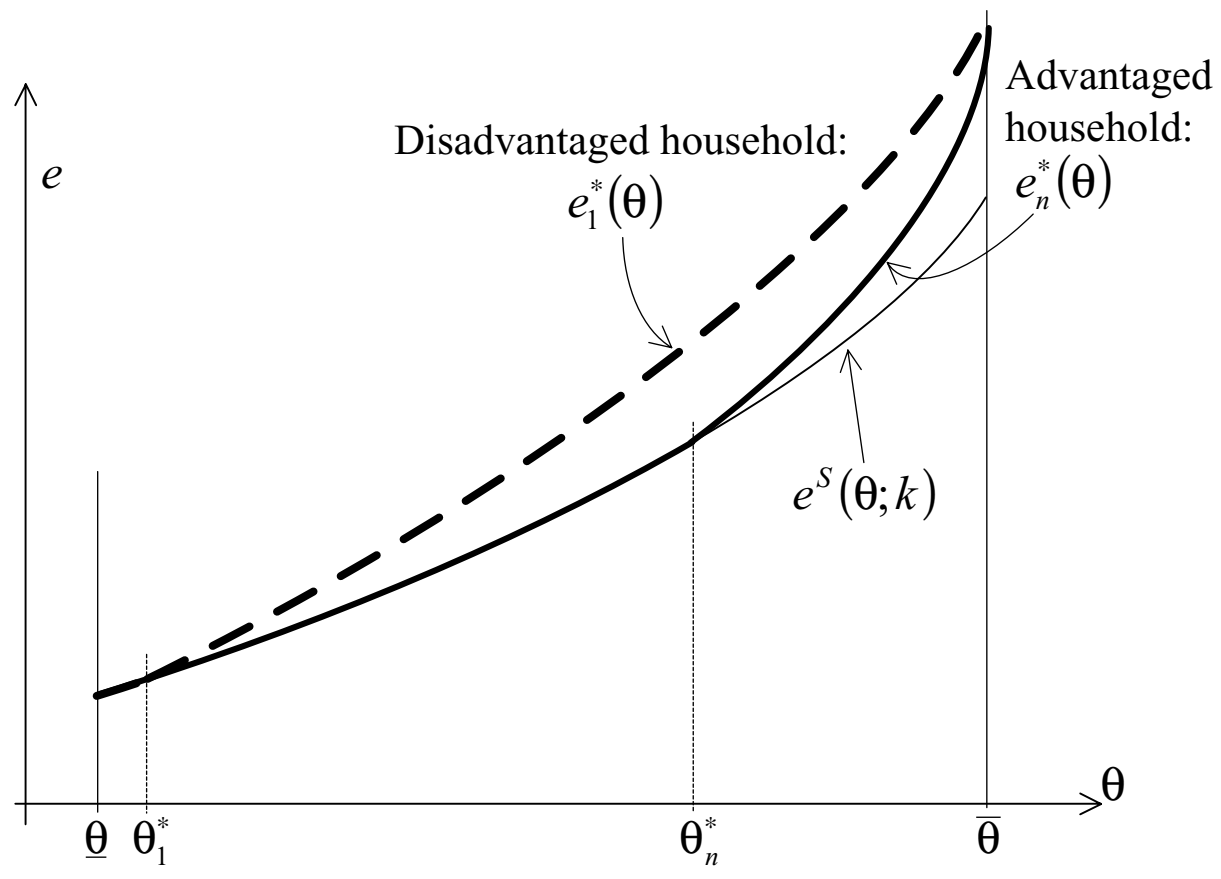

FIGURE 1

THE OPTIMAL EDUCATION LEVEL FOR TWO GROUPS OF INDIVIDUALS

solid (respectively, dashed) line depicts the education level received by individuals coming from the most advantaged (respectively, the most disadvantaged) households. The two lines meet at $\theta=\bar{\theta}$ : Individuals with the highest potential to benefit all receive the same education, irrespective of their group, given by the level where the marginal benefit of the investment in education equals the marginal social cost ("efficiency at the top": See (12), which shows that $y_{e}\left(\theta, e_{i}^{*}(\bar{\theta}), E\right)=k^{*}$ for every $i=1, \ldots, n)$. The education received by lower $\theta$ individuals declines as $\theta$ decreases, but, as illustrated in Figure 1, it declines less rapidly for disadvantaged groups: Therefore, for sufficiently high $\theta$ (above the intersection of the higher of the two curves with the private education level) individuals from disadvantaged groups receive more education than individuals from advantaged groups with the same potential to benefit from education. The curves depicting the education received by individuals in the other groups are between the two curves drawn in Figure 1.

A different interpretative angle for the result in Proposition 2 is obtained if we draw a horizontal line from a given point on the vertical axis. The corresponding points on the horizontal axis give the potential to benefit individuals who receive the same education level, that is, those who are enrolled in the same "school class" or "degree course" for the different groups. According to Proposition 2, the optimal policy is such that, in a given class (below the very top and above 
the lower levels of education), individuals from disadvantaged group have lower labor market potential than their classmates from more advantaged groups. This implies that an empirical analysis of labor market outcomes in the presence of the optimal education policy would show that the (posteducation) labor market income of individuals from disadvantaged groups is lower than the labor market income of their classmates from more advantaged groups. This, of course, corresponds to the empirical findings by Herrnstein and Murray (1994, p. 323), who, however, interpret it as an indictment of higher education policies in the United States. ${ }^{14}$ When $\theta$ is interpreted as ability and when, as Herrnstein and Murray argue, ability is differently distributed in the various ethnic groups, this also tallies with their claim that in the elite universities the average ability of students from disadvantaged backgrounds is lower than for other groups $\left(1994\right.$, p. 472) ${ }^{15}$

We can now turn to the proof of Proposition 2. It hinges on the following lemma, which also has independent interest.

Lemma 1. At the solution of problem (11),

$$
e_{i}^{G}\left(\theta ; \beta, k^{*}\right) \gtreqless e_{j}^{G}\left(\theta ; \beta, k^{*}\right) \text { according to } \frac{1-\Phi_{i}(\theta)}{\phi_{i}(\theta)} \lesseqgtr \frac{1-\Phi_{j}(\theta)}{\phi_{j}(\theta)}
$$

Proof. Let $i>j$. To lighten notation, write $e_{i}=e_{i}^{G}\left(\theta ; \beta, k^{*}\right)$ and $e_{j}=e_{j}^{G}(\theta ; \beta$, $k^{*}$ ). Relationship (12) for the two groups considered becomes

$$
\begin{aligned}
& y_{e}\left(\theta, e_{i}, E\right)-k^{*}=\frac{\beta-1}{\beta} \frac{1-\Phi_{i}(\theta)}{\phi_{i}(\theta)} y_{e \theta}\left(\theta, e_{i}, E\right) \\
& y_{e}\left(\theta, e_{j}, E\right)-k^{*}=\frac{\beta-1}{\beta} \frac{1-\Phi_{j}(\theta)}{\phi_{j}(\theta)} y_{e \theta}\left(\theta, e_{j}, E\right)
\end{aligned}
$$

Subtract the second from the first, and add and subtract the term

$$
\frac{\beta-1}{\beta} \frac{1-\Phi_{i}(\theta)}{\phi_{i}(\theta)} y_{e \theta}\left(\theta, e_{j}, E\right)
$$

\footnotetext{
${ }^{14}$ Note, moreover, that their analysis has been criticized on methodological grounds by Neal and Johnson (1996), Cavallo et al. (1997), and Cawley et al. (1997).

15 Other "utility costs," such as the perpetuation of racial stereotypes implied by the observation of lower achievement by individuals in certain groups (Murray, 1994) or the sense of despair felt by minority students who find themselves in environments where they are unable to compete (D'Souza, 1991), could be explicitly taken into account in the individual utility functions. To do so would dampen, without eliminating altogether, the differences in provision for individuals in different groups. Moreover, the wide-ranging investigation by Bowen and Bok (1998, especially pp. 191-217) fails to unearth convincing evidence of these costs.
} 


$$
\begin{aligned}
y_{e}\left(\theta, e_{i}, E\right)-y_{e}\left(\theta, e_{j}, E\right)=\frac{\beta-1}{\beta}[ & \frac{1-\Phi_{i}(\theta)}{\phi_{i}(\theta)}\left[y_{e \theta}\left(\theta, e_{i}, E\right)-y_{e \theta}\left(\theta, e_{j}, E\right)\right] \\
+ & {\left.\left[\frac{1-\Phi_{i}(\theta)}{\phi_{i}(\theta)}-\frac{1-\Phi_{j}(\theta)}{\phi_{j}(\theta)}\right] y_{e \theta}\left(\theta, e_{j}, E\right)\right] }
\end{aligned}
$$

Applying twice the mean value theorem, there exist $\hat{e}$ and $\tilde{e}$ such that the above can be written as

$$
\begin{aligned}
y_{e e}(\theta, \hat{e}, E)\left(e_{i}-e_{j}\right)=\frac{\beta-1}{\beta}[ & \frac{1-\Phi_{i}(\theta)}{\phi_{i}(\theta)} y_{e e \theta}(\theta, \tilde{e}, E)\left(e_{i}-e_{j}\right) \\
+ & {\left.\left[\frac{1-\Phi_{i}(\theta)}{\phi_{i}(\theta)}-\frac{1-\Phi_{j}(\theta)}{\phi_{j}(\theta)}\right] y_{e \theta}\left(\theta, e_{j}, E\right)\right] }
\end{aligned}
$$

or

$$
\begin{gathered}
{\left[\frac{\beta}{\beta-1} y_{e e}(\theta, \hat{e}, E)-\frac{1-\Phi_{i}(\theta)}{\phi_{i}(\theta)} y_{e e \theta}(\theta, \tilde{e}, E)\right]\left(e_{i}-e_{j}\right)} \\
=\left\{\frac{1-\Phi_{i}(\theta)}{\phi_{i}(\theta)}-\frac{1-\Phi_{j}(\theta)}{\phi_{j}(\theta)}\right\} y_{e \theta}\left(\theta, e_{j}, E\right)
\end{gathered}
$$

We have $y_{e e}(\theta, \hat{e}, E)<0$ and $y_{e e \theta}(\theta, \tilde{e}, E)>0$, implying that the term in the square brackets in (14) is negative. ${ }^{16}$ Therefore, the sign of $\left(e_{i}-e_{j}\right)$ is the opposite of the sign of the term in the curly brackets. This establishes the lemma.

To complete the proof of Proposition 2 simply invoke Assumption 1(a).

By Lemma 1, given two individuals with the same potential to benefit from education belonging to different groups, which of the two should receive more education depends exclusively on the distribution of labor market opportunities in the groups to which these individuals belong.

3.3. Interpretation. Although the result in Proposition 2 may appear surprising, the intuition underlying it is relatively natural. To present it as clearly as possible, we investigate some further features of the optimal policy. These also have an independent interest. The first result illustrates that, with symmetric information, all individuals with the same potential to benefit receive the same education.

\footnotetext{
${ }^{16}$ Lest it be thought that the result depends crucially on the sign of the third cross-derivative $y_{e e \theta}(\cdot)$, note that, for the lemma to hold, it is necessary and sufficient that the term in the square brackets on the LHS of (14) is negative. But as can be seen from the proof of Proposition 1, the negativity of this term is a necessary condition for $e_{i}^{*}(\theta)$ to be increasing, which is a constraint to problem (11). In other words, in order for problem (11) to have the solution identified in Proposition 1, the term in the square bracket in (14) must be negative.
} 
Corollary 1. Suppose the government can costlessly observe $\theta$. Then the optimal policy satisfies

$$
e_{i}^{*}(\theta)=e^{S}\left(\theta ; k^{*}\right) \quad \text { for every } \quad i=1, \ldots, n \quad \theta \in[\underline{\theta}, \bar{\theta}]
$$

Proof. The government problem in this case is obtained from problem (11) by eliminating constraint (8), and the result follows immediately from the proof of Proposition 1, by setting the Pontagryin multiplier $\mu_{i}(\theta)$ identically to 0 .

That is, with no information asymmetry, everybody receives education up to the point where their private benefit, $y_{e}(\cdot)$, equals the-endogenously determinedsocial marginal cost, $k^{*}$.

The next result derives the individual rent. Denote by $U_{i}^{*}(\theta)$ the utility gain, relative to income, $Y$, obtained at the solution of problem (11) by a household in group $i$ where the child has potential $\theta$ to benefit from education.

Corollary 2. Let Assumption 1(a) hold; then $U_{i-1}^{*}(\theta)>U_{i}^{*}(\theta)$ for every $i=$ $2, \ldots, n$, and for every $\theta \in\left(\theta_{i-1}^{*}\left(\beta, k^{*}\right), \bar{\theta}\right]$.

Proof. Note that $\theta_{i-1}^{*}<\theta_{i}^{*}$ (omitting the argument $\left(\beta, k^{*}\right)$ ), and, therefore, for $\theta \in\left(\theta_{i-1}^{*}, \theta_{i}^{*}\right)$ we have $U_{i-1}^{*}(\theta)>U_{i}^{*}(\theta)$, and, in particular, $U_{i-1}^{*}\left(\theta_{i}^{*}\right)>U_{i}^{*}\left(\theta_{i}^{*}\right)$. Next consider $\theta \in\left(\theta_{i}^{*}, \bar{\theta}\right)$. Here we have

$$
\frac{d U_{i-1}^{*}(\theta)}{d \theta}=y_{\theta}\left(\theta, e_{i-1}^{*}(\theta), E\right)>y_{\theta}\left(\theta, e_{i}^{*}(\theta), E\right)=\frac{d U_{i}^{*}(\theta)}{d \theta}
$$

The inequality follows from the fact that $e_{i-1}^{*}(\theta)>e_{i}^{*}(\theta)$ and $y_{e \theta}(\theta, e, E)>0$. But clearly, $U_{i-1}^{*}\left(\theta_{i}^{*}\right)>U_{i}^{*}\left(\theta_{i}^{*}\right)$ and $d U_{i-1}^{*}(\theta) / d(\theta)>d U_{i}^{*} \theta / d \theta$ imply the corollary.

That is, at the optimal policy, households in disadvantaged groups receive, ceteris paribus, a greater utility gain, relative to their income.

Figure 2 illustrates the corollary: It depicts the utility-income differences apart-received by individuals in two groups of households. As before, the solid (respectively, dashed) line depicts the utility of individuals coming from the most advantaged (respectively, the most disadvantaged) households. Households in group $i$ receive utility equal to what they can obtain privately up to $\theta_{i}^{*}\left(\beta, k^{*}\right)$ and higher utility if their children have labor market opportunity above that level.

We can now present the intuition for Proposition 2. Note, to begin with, that the households where the child has high potential to benefit from education receive more utility than the utility they would receive from private provision, depicted in Figure 2 as the thin line $P(\theta, E)$. This additional utility, and the incentive to acquire more education than the private level, is provided in the form of subsidized education: For $\theta>\theta_{i}^{*}\left(\beta, k^{*}\right)$, the tuition fee charged to a type $\theta$ individual from group $i, f_{i}(\theta)$, is less than the cost of her education, $k e_{i}(\theta)$ (see De Fraja, 2002, Proposition 4, p. 463). But, to the extent that the government budget constraint is binding, this subsidy has a social cost, and therefore the government attempts 


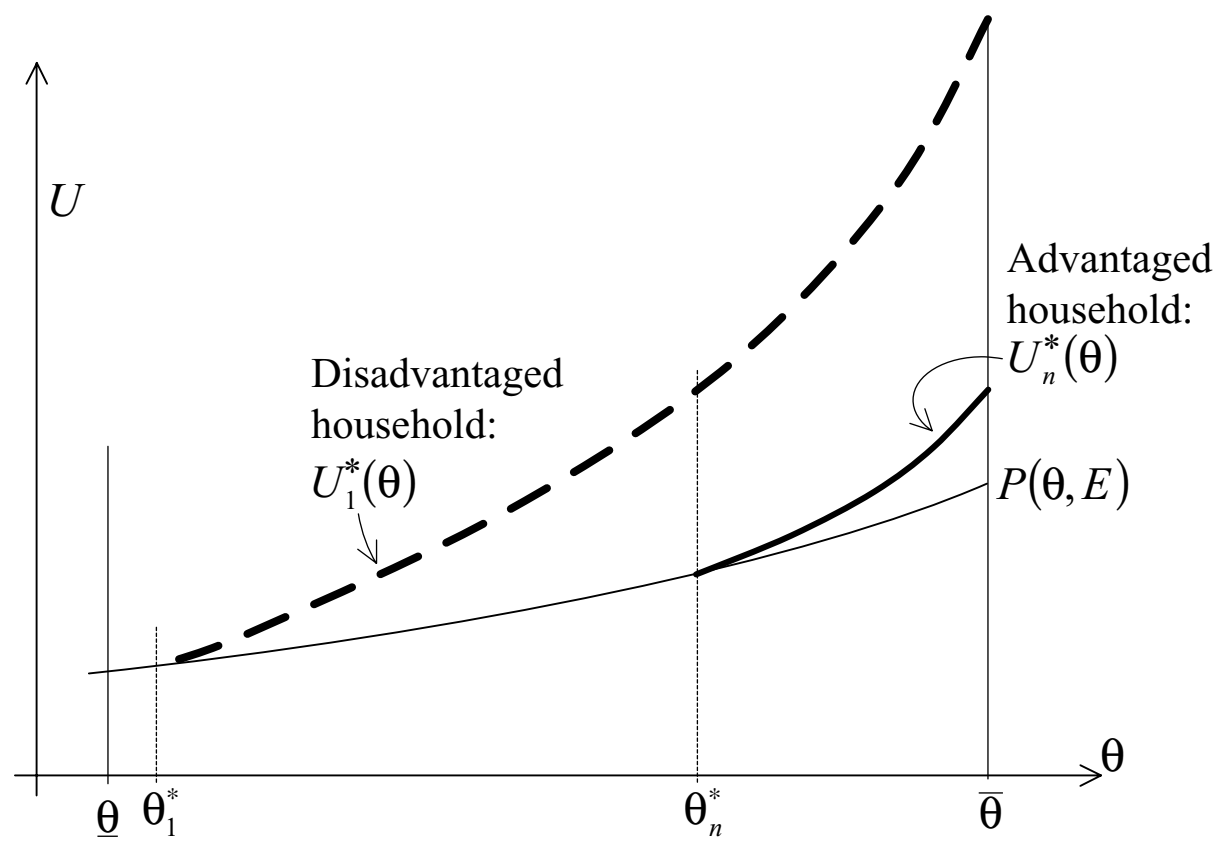

Figure 2

UTILITY FOR TWO GROUPS OF HOUSEHOLDS

to reduce it by reducing sharply the education offered to individuals with progressively lower $\theta$, as described in the discussion following Proposition 2. Note that this does not happen in conditions of symmetric information, (Corollary 1 ), or when the shadow cost of public funds is 1 ( $\operatorname{set} \beta=1$ in (12)): In both these cases, rent extraction is not a concern, and the education received by each individual is independent of her group. With asymmetric information and costly public funds, however, there is a trade-off between the social cost of the rent received by high $\theta$ individuals and the social cost of distorting the education received by lower $\theta$ individuals. But now, and here is the crux of the argument, notice that the relative weight of these costs in the social welfare function is determined by the relative number of individuals of different potential to benefit from education. Take a given level of $\theta<\bar{\theta}$, say $\theta_{0}$; take a small interval $\left(\theta_{0}-\varepsilon, \theta_{0}+\varepsilon\right)$ : There are $\Phi_{i}\left(\theta_{0}+\varepsilon\right)-\Phi_{i}\left(\theta_{0}-\varepsilon\right) \cong 2 \varepsilon \phi_{i}\left(\theta_{0}\right)$ individuals with this value of $\theta$ in this group, and $1-\Phi_{i}\left(\theta_{0}\right)$ individuals with $\theta$ above $\theta_{0}$. Therefore, the number of individuals with $\theta$ above $\theta_{0}$ per individual with $\theta=\theta_{0}$, is (proportional to) precisely the hazard rate, $\left[1-\Phi_{i}\left(\theta_{0}\right)\right] / \phi_{i}\left(\theta_{0}\right)$. Because of Assumption 1, the hazard rate is smaller in a disadvantaged group than in an advantaged group. But this implies that there are fewer individuals with $\theta$ above $\theta_{0}$ per individual with potential to benefit $\theta_{0}$ in groups with a lower hazard rate, and therefore, in aggregate, it is relatively less costly to give more rent to the high $\theta$ individuals in a group with a lower hazard rate in order to reduce the social loss given by the reduction in education below the social optimum for type $\theta_{0}$ individuals in that group. And this is exactly what 
Proposition 2 says. Conversely, if a group has a high hazard rate, then it has more above $\theta_{0}$ individuals per $\theta_{0}$ individual, and the social saving obtained by reducing their informational rent becomes relatively more attractive than the social cost incurred by reducing the education level offered to lower $\theta$ individuals.

3.4. Financial Contribution. It is now fairly simple to derive the relationship between the level of education received and the tuition fee paid. Within a group, the analysis is essentially identical to the standard model of incentives under asymmetric information (Laffont and Tirole, 1993, pp. 69-70), which shows that the optimal policy can be implemented by offering all households in a given group an appropriately designed menu of contracts. In our model, this means an appropriately designed schedule of fees for the possible education levels. The lines in Figure 3 illustrate the situation for groups 1 and $n$ : The locus $F_{i}(e)$ denotes the fee paid by individuals in group $i$ for choosing the education level $e, i=1, n$. It is straightforward to show (Laffont and Tirole, 1993, pp. 69-70) that if $F_{i}\left(e_{i}^{*}(\theta)\right)=$ $f_{i}^{*}(\theta) \equiv y\left(\theta, e_{i}^{*}(\theta), E\right)-U_{i}(\theta)+Y+u\left(b^{*}\right)-b^{*}$, for every $\theta \in[\underline{\theta}, \bar{\theta}]$, then households of type $\theta$ in group $i$ choose the combination $\left\{e_{i}^{*}(\theta), f_{i}^{*}(\theta)\right\}$, and that the locus is increasing and concave, as shown. More central to the topic of this article is the relationship between the schedules for different groups. Proposition 3 establishes that households in disadvantaged groups are required to pay a lower fee for the same education, as depicted in Figure 3.

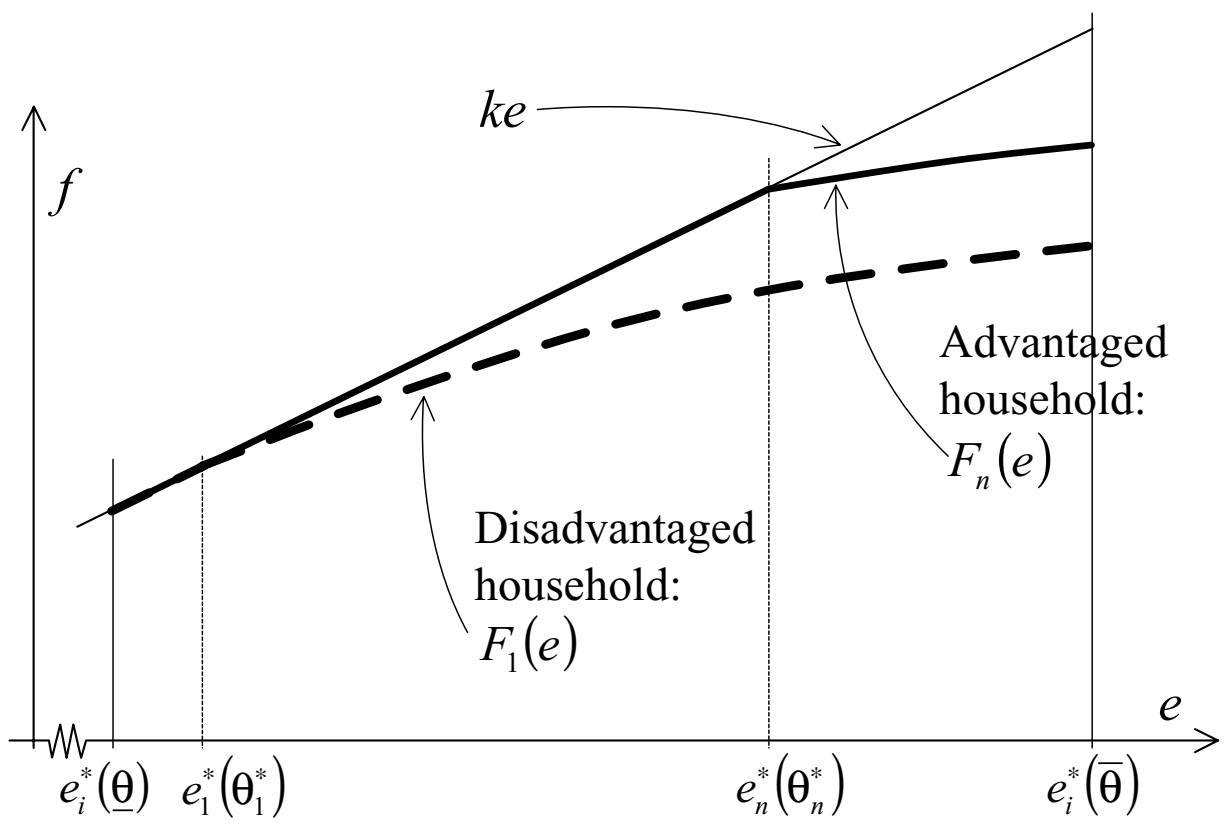

FIGURE 3 
Proposition 3. Let $F_{i}(e)$ and $F_{j}(e)$ be the fee schedule available to households in groups $i$ and $j$, respectively, with $i<j$. Then $F_{i}(e) \leqslant F_{j}(e)$, with strict inequality for $e>e_{i}^{*}\left(\theta_{i}^{*}\right)$.

Proof. We need to consider three regions, $e \leqslant e_{i}^{*}\left(\theta_{i}^{*}\right), e \in\left(e_{i}^{*}\left(\theta_{i}^{*}\right), e_{j}^{*}\left(\theta^{*}{ }_{j}\right)\right]$, and $e>e_{j}^{*}\left(\theta_{j}^{*}\right)$. In the first $\theta<\theta_{i}^{*}$, and so $e_{i}^{*}(\theta)=e_{j}^{*}(\theta)=e^{S}(\theta ; k)$ and $U_{i}(\theta)=$ $U_{j}(\theta)$. Here, therefore, $F_{i}(e)=F_{j}(e)$. Consider the third region. Here both groups receive an education level strictly above what they would receive privately (in the second region this is the case only for the advantaged group, and the argument is essentially the same, if notationally slightly more complicated). Take $\hat{e}>e_{j}^{*}\left(\theta_{j}^{*}\right)$. Let $\hat{\theta}_{i}$ and $\hat{\theta}_{j}$ be the corresponding values of $\theta: \hat{e}=e_{i}^{*}\left(\hat{\theta}_{i}\right)=e_{j}^{*}\left(\hat{\theta}_{j}\right)$. We want to show that $f_{i}^{*}\left(\hat{\theta}_{i}\right)<f_{j}^{*}\left(\hat{\theta}_{j}\right)$. Substitute the values of $f_{i}^{*}\left(\hat{\theta}_{i}\right)$ and $f_{j}^{*}\left(\hat{\theta}_{j}\right)$ from (6) to obtain

$$
f_{j}^{*}\left(\hat{\theta}_{j}\right)-f_{i}^{*}\left(\hat{\theta}_{i}\right)=\left[y\left(\hat{\theta}_{j}, \hat{e}, E\right)-y\left(\hat{\theta}_{i}, \hat{e}, E\right)\right]-\left[U_{j}\left(\hat{\theta}_{j}\right)-U_{i}\left(\hat{\theta}_{i}\right)\right]
$$

The term in the first square brackets can be written as $\int_{\hat{\theta}_{i}}^{\hat{\theta}_{j}} y_{\theta}(\tilde{\theta}, \hat{e}, E) d \tilde{\theta}$. Therefore, adding and subtracting $U_{j}\left(\hat{\theta}_{i}\right),(15)$ can be written as

$$
f_{j}^{*}\left(\hat{\theta}_{j}\right)-f_{i}^{*}\left(\hat{\theta}_{i}\right)=\int_{\hat{\theta}_{i}}^{\hat{\theta}_{j}} y_{\theta}(\tilde{\theta}, \hat{e}, E) d \tilde{\theta}-\left[U_{j}\left(\hat{\theta}_{j}\right)-U_{j}\left(\hat{\theta}_{i}\right)\right]-\left[U_{j}\left(\hat{\theta}_{i}\right)-U_{i}\left(\hat{\theta}_{i}\right)\right]
$$

Note that the term in the first square brackets on the RHS of the above is

$$
\int_{\theta_{j}^{*}}^{\hat{\theta}_{j}} y_{\theta}\left(\tilde{\theta}, e_{j}^{*}(\tilde{\theta}), E\right) d \tilde{\theta}-\int_{\theta_{j}^{*}}^{\hat{\theta}_{i}} y_{\theta}\left(\tilde{\theta}, e_{j}^{*}(\tilde{\theta}), E\right) d \tilde{\theta}=\int_{\hat{\theta}_{i}}^{\hat{\theta}_{j}} y_{\theta}\left(\tilde{\theta}, e_{j}^{*}(\tilde{\theta}), E\right) d \tilde{\theta}
$$

and that, since $\hat{e}=e_{j}^{*}\left(\hat{\theta}_{j}\right)$, the RHS of (15) can be written as

$$
\left[\int_{\hat{\theta}_{i}}^{\hat{\theta}_{j}} y_{\theta}\left(\tilde{\theta}, e_{j}^{*}\left(\hat{\theta}_{j}\right), E\right) d \tilde{\theta}+\int_{\hat{\theta}_{i}}^{\hat{\theta}_{j}} y_{\theta}\left(\tilde{\theta}, e_{j}^{*}(\tilde{\theta}), E\right) d \tilde{\theta}\right]+\left[U_{i}\left(\hat{\theta}_{i}\right)-U_{j}\left(\hat{\theta}_{i}\right)\right]
$$

The term in the first square bracket is positive because $\hat{\theta}_{j}>\tilde{\theta}$ for $\tilde{\theta} \in\left[\hat{\theta}_{i}, \hat{\theta}_{j}\right)$, and $y_{\theta e}(\cdot)>0$, the second is positive by Corollary 2. This establishes Proposition 3 .

We end the article with a remark that tempers somehow the reverse discrimination flavor of the article. Although it is clear that an individual from a disadvantaged group makes a bigger claim on the total budget of the education sector, $T$, than an otherwise identical individual from a more advantaged group, it is ambiguous whether a disadvantaged group as a whole also has a bigger claim than a more advantaged group. Formally, this can be seen by noting that the total rent of group $i$ is given by $\int_{\theta_{i}^{*}}^{\bar{\theta}}\left[U_{i}(\tilde{\theta})-P(\tilde{\theta}, E)\right] \phi_{i}(\tilde{\theta}) d \tilde{\theta}$, and that the difference between 
the value of this expression for two different groups cannot be determined in general.

\section{CONCLUSION}

The article derives the optimal education policy in the presence of groups that differ according to the distributions of individuals' potential to benefit from education. Because of asymmetric information, the first-best policy cannot be implemented. The second-best optimal policy is an instance of reverse discrimination: It favors individuals from disadvantaged backgrounds, who need a lower potential benefit to receive a given education level and who pay a lower fee for the same education than individuals from more advantaged backgrounds. Implementation of the policy can be achieved in practice through financial assistance program that are differentiated according to the group of appurtenance of applicants. We stress the efficiency viewpoint of the article, which derives these policies not from a sense of justice or fairness or from the desire of righting past wrongs, but from a dispassionate calculation of society's costs and benefits, using the viewpoint (standard in normative analysis in public economics) of a utilitarian welfare function. ${ }^{17}$

Our result holds irrespective of the reason why one group is disadvantaged. Indeed, paradoxically, if differences in labor market opportunity between groups are due to differences in the distribution of innate ability between individuals in various groups (be they genetically or environmentally determined) that are unavoidable and will not be changed by conscious policy intervention, then the bias in education policy favoring disadvantaged groups illustrated in Propositions 2 and 3 should also be persistent. If, on the other hand, differences in the distribution of labor market opportunity can be reduced by other forms of intervention, the optimal education policy would tend to become "group blind": The two curves in Figures 1-3 would tend to converge to a single one, in line, for example, with the view expressed by U.S. Supreme Court Justice O'Connor, who "expect[s] that 25 years from now, the use of racial preferences will no longer be necessary". ${ }^{18}$

\section{REFERENCES}

Becker, G. S., The Economics of Discrimination (Chicago: University of Chicago Press, 1971).

Bertola, G., And D. Checchi, "Sorting and Private Education in Italy," Lavoro e Relazioni Industriali 2 (2001), 87-124.

Blaug, M., "The Rate of Return on Investment in Education in Great Britain," Manchester School 33 (1965), 205-51.

Bowen, W. G., AND D. Вок, The Shape of the River: Long-Term Consequences of Considering Race in College and University Admissions (Princeton, NJ: Princeton University Press, 1998).

\footnotetext{
${ }^{17}$ Note in particular that diversity in the student body composition does not per se enter the decision maker's objective function. The articles by Chan and Eyster (2004) and Epple et al (2004) show that explicit reverse discrimination can lessen the inefficiency associated with admission policies when universities have a preference for diversity.

${ }^{18}$ Grutter v. Bollinger, No. 02-241 (S.Ct. June 23, 2003) at 64.
} 
Cavallo, A., H. El-Abbadi, and R. Heeb, "The Hidden Gender Restriction: The Need for Proper Controls when Testing for Racial Discrimination," in B. Devlin, S. E. Fienberg, D. P. Resnick, and K. Roeder, eds., Intelligence, Genes, and Success (New York: Springer Verlag, 1997), pp. 193-214.

Cawley, J., K. Conneely, J. Heckmann, and E. Vytlacil, "Cognitive Ability, Wages, and Meritocracy," in B. Devlin, S. E. Fienberg, D. P. Resnick, and K. Roeder, eds., Intelligence, Genes, and Success (New York: Springer Verlag, 1997), pp. 179-92.

Chan, J., And E. Eyster, "Does Banning Affirmative Action Harm College Quality?" American Economic Review 94 (2004), 858-72.

Coate, S., AND G. C. Loury, "Will Affirmative-Action Policies Eliminate Negative Stereotypes?" American Economic Review 83 (1993), 1220-40.

Conn, E., The Economics of Education (Cambridge, MA: Ballinger, 1975).

DARITY, W. A. JR., AND P. L. MAson, "Evidence of Discrimination in Employment: Codes of Color, Codes of Gender," Journal of Economic Perspectives 12 (1998), 6390.

De Fraja, G., "The Design of Optimal Education Policies," Review of Economic Studies 69 (2002), 437-66.

DfES, "The Future of Higher Education," Department for Education and Skills, HMSO, London, Cm 57352003.

D'souzA, D., Illiberal Education (New York: Free Press, 1991).

Epple, D., R. Romano, and H. Sieg, "The Practice and Proscription of Affirmative Action in Higher Education: An Equilibrium Analysis," NBER Discussion Paper 9799, New York, 2004.

Hanushek, E. A., "Publicly Provided Education," in A. J. Auerbach and M. Feldstein, eds., Handbook of Public Economics, Volume 4 (Amsterdam: North Holland, 2002), pp. 2046-141.

Herrnstein, R. J., And C. Murray, The Bell Curve: Intelligence and Class Structure in American Life (New York: The Free Press, 1994).

Holzer, H., And D. Neumark, "Assessing Affirmative Action," Journal of Economic Literature 38 (2000), 483-568.

LADD, H. F., "Evidence of Discrimination in Mortgage Lending," Journal of Economic Perspectives 12 (1998), 41-62.

Laffont, J.-J., and J. Tirole, A Theory of Incentives in Procurement and Regulation (Cambridge, MA: MIT Press, 1993).

Leonard, D., and N. van Long, Optimal Control Theory and Static Optimization in Economics (Cambridge: Cambridge University Press, 1992).

Loury, G. C., The Anatomy of Racial Inequality (Cambridge, MA: Harvard University Press, 2002).

LucAs, R. J., "On the Mechanics of Economic Development," Journal of Monetary Economics 22 (1988), 3-42.

Lundberg, S. J., and R. Starz, "Private Discrimination and Social Intervention in Competitive Labor Markets," American Economic Review 73 (1983), 340-47.

Milgrom, P., AND S. Oster, "Job Discrimination, Market Forces and the Invisibility Hypothesis," Quarterly Journal of Economics 102 (1987), 453-76.

Moretri, E., "Estimating the Social Return to Higher Education: Evidence from Longitudinal and Repeated Cross-sectional Data," Journal of Econometrics 121 (2004), $175-212$.

Murray, C., "Affirmative Racism," in N. Mills, ed., Debating Affirmative Action: Race Gender Ethnicity and the Policy of Inclusion (New York: Delta, 1994), pp. 191208.

Neal, D., And W. Johnson, "The Role of Premarket Factors in Black-White Wage Differentials," Journal of Political Economy 104 (1996), 869-95.

Rubinstein, Y., and D. Tsiddon, "Coping with Technological Progress: The Role of Ability in Making Inequality so Persistent," mimeo, Tel Aviv University, 1998. 
Solon, G., "Intergenerational Mobility in the Labor Market," in O. C. Ashenfelter and D. Card, eds., Handbook of Labor Economics, Volume 3A (Amsterdam: North Holland, 1999), pp. 1761-800.

Stephanopoulos, G., And C. Edley, "Review of Federal Affirmative Action Programs," White House, Washington, DC, 1995.

West, E. G., "The Role of Education in Nineteenth-Century Doctrines of Political Economy," British Journal of Educational Studies 12 (1964), 161-72.

Wickelgren, A. L., "The Efficiency of Affirmative Action with Purely Historical Discrimination," Federal Trade Commission, Washington, DC, 2002.

YINGER, J., "Evidence of Discrimination in Consumer Markets," Journal of Economic Perspectives 12 (1998), 23-40. 